Having traced the progress of the epidemic from Afghanistan to Persia with great probability, and from Persia to Russia in Asia, and from Russia in Asia to Russia in Europe with precision, it remains to inquire how the infection reached Afghanistan. As to this, there is room for some differences of opinion. It is natural, in the first instance, to turn our thoughts to the Hurdwâr fair, the continuance of which the Government of India found it advisable this year to prohibit, on account of the danger of the dissemination of cholera. This great assembly of people, brought together primarily by a religious object, is frequented by pilgrims and traders from the North-West Provinces, by Kashmirees and border men. The prohibition was not completely effective, and many of those who reached Hurdwâr at an early date, or eluded the vigilance of the officials at a later, undoubtedly carried cholera for considerable distances. There is strong reason to believe, though the fact cannot be affirmed positively, that the disease was thus conveyed to Srinagar, the capital of Kashmir, where a severe outbreak began in May. While it will be admitted that the accumulation of a huge multitude of people at Hurdwâr in the early spring, and their dispersal in every direction throughout north-western India and the frontier countries, is a fact, the significance of which for Europe is greatly increased by the proof now afforded that cholera may be carried in a few weeks from the confines of Afghanistan to European Russia, yet it appears that the Hurdwâr fair is not in any way responsible for the movement of cholera this year.

As has already been said, cholera was epidemic in Afghanistan at the end of 1891. A month or two earlier-in September-an outbreak had occurred among labourers in the Hoti Mardan district of the Peshawar division. There appears to be little doubt that this outbreak was originated by men coming from Swat and other independent territories to the north-east of Peshawar. The labourers immediately dispersed, many fleeing to Peshawar, where an epidemic of a peculiarly fatal character subsequently occurred, both in the town and in the Pathan villages in the immediate neighbourhood. The mortality in some of the villages in the valleys towards the eastern mouth of the Khyber pass was particularly severe. At a later date many villages in the Shinwarri country lying to the north of the western end of the pass were ravaged, and towards the end of the year Cabul itself was attacked, as already said.

It does not seem to be necessary to refer at any length to the spread of the epidemic at Hamburg; its dependence upon the line of emigration from Russia appears to be obvious, and the probability of the occurrence of cases among emigrants arriving at that port from infected districts en route for England and America ought to have been foreseen and provided for by the authorities in Hamburg. This does not seem to have been the case, and insanitary conditions appear to have been allowed to prevail, of which we now see the inevitable consequences. Neither does it come within the scope of the present paper to discuss the nature of the choleraic disease which began to prevail in Paris in the early summer. Its epidemiological characters were not those of Asiatic cholera.

In conclusion I would venture to make the following observations :-

1. The greater rapidity of transit has increased the probability of the importation of cholera and other epidemic diseases from Central Asian countries to European Russia, and thence to Europe in general.

2. Asiatic cholera, in travelling by land routes, depends for its power of continued progress mainly upon the existence of insanitary conditions in towns in which traffic is temporarily arrested for trans-shipment or otherwise. The necessary delay affords time for persons from infected districts to be attacked by the disease, and so to infect the place at which the halt is made. Such places become fresh centres from which the disease spreads along lines of traffic. This fact is well illustrated by the history of the present epidemic in Baku and in Hamburg.

3. Quarantine has once more shown itself to be a most ineffectual method of checking the spread of cholera. Quarantine, for instance, between Baku and Astrakhan utterly failed to prevent the spread of the infection to the latter town.
4. On the other hand, medical inspection of travellers, especially of those of the poorer emigrant class, combined with isolation of doubtful cases, appears to be once more showing itself to be an effectual method. At the same time, it must be recognised that no method can be effectual in the absence of good sanitary conditions in ports or other centres of trans-shipment or temporary arrest of traffic. In fact, it may almost be said that the only effectual method of excluding cholera from a country is to exclude the infectious principles from its water supplies.

5 . The need for more precise, earlier, and more authoritative information as to the existence of epidemic diseases in all civilised countries is urgent, and, pending the organisation of an international understanding upon the subject, it appears to be desirable to urge upon the Government of this country the creation of an Epidemic Intelligence Department in connection with the Lncal Government Board, which should collect and collate the information in the possession of that Board, of the Board of Trade, and of the Foreign Office.

6. The presence of Asiatic cholera this summer and autumn on the Trans-Caucasian Railway should not be lost sight of, as a recrudescence may occur next spring and lead to infection of Batoum and Poti, and thence of other Black Sea ports.

\section{ON THE SPECIFIC GRAVITY OF THE} URINE IN DIABETES MELLITUS.

BY Sir EDWARD H. SIEVEKING, M.D., F.R.C.P., Physician-in-Ordinary to the Queen; Consulting Physician to St. Mary's
Hospital.

ALL our authorities and our individual experience adopt a high specific gravity as an important indication of the presence of sugar in the urine. The following case appears to me to show that our urinometers may exhibit a much lower specific gravity than that ordinarily regarded as causing a suspicion of sugar, and that still sugar may be present. Not being a professed chemist, I naturally began to suspect, in the case about to be related, that my tools were not in proper order, and I therefore sent the urine to my friend Dr. Luff, the Government analyst, with a request for information on this point. His reply was that my tests were quite correct, the specific gravity of the urine 1010, and containing "a small quantity of sugar, the lowest, specific gravity of any urine in which I have detected sugar." He also confirmed the fact of its containing a faint trace of albumen. The case is briefly as follows:-

A lady, aged 61, was sent to me on July 5 th of this year with severe symptoms of stomach derangement. Her histors was to the effect that she had suffered six years previously from diabetes, but that considering herself cured, she had returned to her ordinary mode of living. The day after her first visit, I obtained a specimen of the urine when the specific gravity was 1022; there was some albumen, and Fehling's test gave decided evidence of sugar. On July 7th, in consequence of the treatment, the urine had become alkaline, the specific gravity was reduced to 1012 , there was less albumen, and sugar was still shown to be present. On July 9 th the urine was faintly acid, specific gravity 1010; there was a faint trace of albumen and a well-marked trace of sugar. Her symptoms of dyspepsia had disappeared, so the patient was able again to take substantial food. It was the urine of this day that Dr. Luff was kind enough to examine, and to send me the report I have given above. I saw the lady once more on July 14th, when the specific gravity had risen to 1014 , and the tests still yielded evidence of the presence of both albumen and sugar. I recommended a watering place to my patient, and presume that she has left London, as I have not seen her again.

Although this is undoubtedly an exceptional case, it appears to me to afford a decided warning to us all not to be too much guided by the urinometer alone. The examination of urine is universally regarded as a material help in the diagnosis of disease, but it may be fairly suspected that in many cases we have been too liable to assume that if our urinometers indicated a specific gravity below 1030, we might save ourselves the trouble of applying the tests for sugar. 